\title{
Comparison and evaluation of copper complex-containing siloxane polymers as stationary phases for capillary gas chromatography
}

\author{
Chuen-Ying Liu*, Sheng-Hsiung Yang, Mao-Hsing Chau, Chia-Chann Shiue \\ Department of Chemistry, National Taiwan University, Taipei, Taiwan
}

Received 7 December 2000; received in revised form 5 March 2001; accepted 16 August 2001

\begin{abstract}
Two metallomesogenic polymers, $\mathrm{P}-\mathrm{C}_{11} \mathrm{CuC}_{18}$ and $\mathrm{P}-\mathrm{C}_{11} \mathrm{CuC}_{12}$ consisting of flexible aliphatic side chains with copper carboxylate complexes have been synthesized on the basis of addition reactions with polysiloxane. The applicability of the prepared columns to the analysis of phthalate esters that are of environmental concern was assessed. For preparation of the capillary column with its wall coated with the metallomesogenic polymer, both static and dynamic methods were employed. Factors affecting the retention and the sample selectivity on both columns were examined. A better separation of phthalates was achieved with $\mathrm{P}_{-} \mathrm{C}_{11} \mathrm{CuC}_{18}$ than $\mathrm{P}_{-} \mathrm{C}_{11} \mathrm{CuC}_{12}$. The former phase showed a higher solute-solvent interaction than the latter. With static coating, the wall-coated $\mathrm{P}-\mathrm{C}_{11} \mathrm{CuC}_{18}$ capillary column $(15 \mathrm{~m} \times 250 \mu \mathrm{m}$ I.D. $)$ showed that the baseline separation of all 14 phthalates could be achieved within $38 \mathrm{~min}$ with high reproducibility. The calibration graphs for phthalate ester determination were linear over the range of $10-625 \mu \mathrm{g} \mathrm{ml}^{-1}$. The mass detection limits were lower than the ng range based on three times the standard deviation of seven measurements of the lowest peak that could be detected. (C) 2001 Elsevier Science B.V. All rights reserved.
\end{abstract}

Keywords: Stationary phases, GC; Metallomesogens; Copper; Phthalate esters; Polysiloxanes

\section{Introduction}

The vast majority of liquid crystalline substances are organic compounds with a rod-like (calamitic) or flat disc-like molecular shape. In recent years, an increasing number of research groups have turned their attention to metal-containing liquid crystals or metallomesogens. In 1984, Giroud-Godquin et al. suggested that the long-chain homologues of copper acetate might exhibit columnar mesophases owing to the adequate symmetry of their central binuclear

*Corresponding author. Fax: +886-2-2363-8543.

E-mail address: cyliu@ccms.ntu.edu.tw (C.-Y. Liu). cores [1]. Since then, Abied et al. began a systematic study on carboxylate complexes which are known to exist as binuclear molecules with two metal atoms bridged by four bidentate carboxylate groups [2]. The introduction of metal atoms provides liquid crystal chemistry and physics with different possibilities. The interesting properties have given rise to expectations of new applications of liquid crystals based on metallomesogens [3].

To meet particular requirements in liquid crystal display industries and other applications, many new liquid crystal polymers have been synthesized [4-8]. Many metallomesogenic structures have also been introduced into polymeric systems. Metallomesogenic polymers can combine the promising 
properties of metallomesogens with the advantageous properties of polymers [9].

In our laboratory, both rod-like and disk-like metallomesogens were found to be highly promising as the stationary phases of gas chromatography (GC) for the separation of environmental pollutants [1013]. The factors responsible for the elution order of most compounds analyzed with these metallomesogens were considered to be vapor pressure of the samples, polarity interaction, ligand exchange and molecular geometry. The separation behaves somewhat like that of the complexation gas chromatography shown in the literature [14-17]. For further insight into the metallomesogens useful in the field of analytical chemistry, a systematic investigation of the molecular structure on the effect of the phase transition was studied.

We report here homologues of the metallomesogenic polymer with $\mathrm{P}-\mathrm{L}_{1} \mathrm{CuL}_{2}$ where $\mathrm{L}_{1}$ is $\mathrm{C}_{11}$ and $L_{2}$ are $C_{12}$ and $C_{18}$. Study of the mesophases of these homologues can give information about the changes of properties of the mesophases with variation of the alkyl chain length. A comparison of similar phases of different homologues can help us gain insight into the orientation of molecules and molecular motions in these phases. Phthalate esters are used as plasticizers in polymeric materials such as polyvinyl chloride used for the production of consumer products and building materials [18-21]. Since there is considerably concern about the widespread occurrence of low levels of phthalate esters as plasticizers and the potential adverse impact of these upon the environment and human health [22,23], the analytical application of these metallomesogenic polymers in this field will also be described.

\section{Experimental}

\subsection{Apparatus}

Elemental analyses were carried out with a PerkinElmer elemental analyzer (Model 2400), provided by the Elemental Analyses Service Center of NSC at the National Taiwan University. IR spectra were obtained on a Bio-Rad spectrophotometer (Model FTS40). Phase transitions were studied by differential scanning calorimetry (DSC) on a TA-2920 ap- paratus, operating through first heating, cooling and second heating ranging from room temperature to $250^{\circ} \mathrm{C}$ at heating rate of $10^{\circ} \mathrm{C} \mathrm{min}{ }^{-1}$ under an $\mathrm{N}_{2}$ flow $\left(100 \mathrm{ml} \mathrm{min}^{-1}\right)$. A TA-2950 type thermogravimetric analyzer was used for the measurement of sample thermal stability under a continuous $\mathrm{N}_{2}$ flow $\left(60 \mathrm{ml} \mathrm{min}^{-1}\right)$ at a rate of temperature rise of $10^{\circ} \mathrm{C} \min ^{-1}$. Hot stage polarized light microscopy was carried out with an Olympus BX-50 microscope equipped with a Unkam TMS-92. The gas chromatograph used throughout for column evaluation was a Shimadzu Model 17A, equipped with a capillary column split injection system and a flame ionization detection (FID) system. Nitrogen was used as the carrier gas. Chromatograms were plotted on a Shimadzu CR-6A Chromatopac integrator.

\subsection{Reagents and chemicals}

Most chemicals were analytical-reagent grade from Merck (Darmstadt, Germany). Purified water (18 $\mathrm{M} \Omega$-cm) from a Milli-Q water purification system (Millipore, Bedford, MA, USA) was used to prepare all solutions. Sodium stearate and sodium laurate (Wako, Japan), 10-undecenoic acid (Lancaster, UK), chloroplatinic acid (Janssen, Belgium), benzoyl peroxide (Merck) as well as poly(methylhydrosiloxane) (PS 122, $M_{n}=4500 \sim 5000$ ) (Petrach Systems, Bristol, PA, USA) were purchased from the indicated sources. All liquid reagents and solvents used in moisture-sensitive reactions were distilled and collected over type $4 \AA$ molecular sieves. All solid materials used in moisture-sensitive reactions were dried at $110^{\circ} \mathrm{C}$ for $24 \mathrm{~h}$ prior to the experiment. The analytes comprising dimethyl phthalate $\left(M_{\mathrm{r}}\right.$, 194.2 ; b.p., $\left.285^{\circ} \mathrm{C}\right)$, diethyl phthalate $\left(222.3 ; 296^{\circ} \mathrm{C}\right)$, diisopropyl phthalate $\left(250.3 ; 298^{\circ} \mathrm{C}\right)$, diisobutyl phthalate $\left(278.4 ; 295-298^{\circ} \mathrm{C}\right)$, di- $n$-butyl phthalate $\left(278.4 ; 340^{\circ} \mathrm{C}\right)$, dimethoxyethyl phthalate $(282.2$; $\left.230^{\circ} \mathrm{C}\right)$, diamyl phthalate $\left(306.4 ; 342^{\circ} \mathrm{C}\right)$, butylbenzyl phthalate $\left(312.4 ; 370^{\circ} \mathrm{C}\right)$, diphenyl phthalate $\left(318.4 ; 405^{\circ} \mathrm{C}\right)$, dicyclohexyl phthalate $\left(330.4 ; 400^{\circ} \mathrm{C}\right)$, diisoheptyl phthalate $(360.5)$, di- $n$ heptyl phthalate $\left(360.5 ; 370^{\circ} \mathrm{C}\right)$, dibutoxyethyl phthalate $\left(366.4 ; 220^{\circ} \mathrm{C}\right)$, di-(2-ethylhexyl) phthalate $\left(390.5 ; 380^{\circ} \mathrm{C}\right)$, di- $n$-octyl phthalate $\left(390.5 ; 380^{\circ} \mathrm{C}\right)$, and dinonyl phthalate $\left(418.6 ; 413^{\circ} \mathrm{C}\right)$ were purchased from TCI (Tokyo, Japan). 


\subsection{Synthesis of the metallomesogenic polymer}

The detailed procedures for the preparation of both sodium stearate and sodium laurate were as reported in Ref. [13]. The polymeric mesogenic phase was prepared by the following procedures:

Poly(methylhydrosiloxane) (0.62 g, $0.125 \mathrm{mmol})$ and 10-undecenoic acid $(1.84 \mathrm{~g}, 10 \mathrm{mmol})$ in dry toluene $(15.5 \mathrm{ml})$ were placed in a round bottom flask. Chloroplatinic acid $\left(\mathrm{H}_{2} \mathrm{PtCl}_{6} \cdot x \mathrm{H}_{2} \mathrm{O}\right)(50 \mathrm{ppm}$, $\mathrm{w} / \mathrm{v})$ in 2-propanol $(0.5 \mathrm{ml})$ was added as catalyst. The reaction mixture was stirred under nitrogen and heated at $50^{\circ} \mathrm{C}$. The heating was continued for $48 \mathrm{~h}$. The reaction extent can be monitored from IR spectra $\left(2169 \mathrm{~cm}^{-1}\right)$ by the amount of $\mathrm{Si}-\mathrm{H}$ remaining in the reaction mixture. When the $\mathrm{Si}-\mathrm{H}$ band could no longer be detected, the reaction was complete. The product is compound I $\left(\mathrm{P}-\mathrm{C}_{11}\right)$.

To compound I, sodium hydroxide $(0.1 M, 100$ $\mathrm{ml})$ was added. Copper sulfate $(2.48 \mathrm{~g})$ and sodium stearate $(0.01 \mathrm{~mol}, 3.06 \mathrm{~g})$ or sodium laurate $(0.01$ mol, $2.22 \mathrm{~g}$ ) were then added sequentially and reacted at $65^{\circ} \mathrm{C}$ with stirring for $4 \mathrm{~h}$. The final products $\left(\mathrm{P}-\mathrm{C}_{11} \mathrm{CuC}_{18}\right.$ and $\left.\mathrm{P}-\mathrm{C}_{11} \mathrm{CuC}_{12}\right)$ were recrystallized from $n$-heptane and dichloromethane. IR for $\mathrm{P}_{-\mathrm{C}_{11}} \mathrm{CuC}_{18}: \rho_{(\mathrm{C}-\mathrm{H})}=727 \mathrm{~cm}^{-1}, v_{(\mathrm{Si}-\mathrm{O}-\mathrm{Si})}=1039$ $\mathrm{cm}^{-1}, v_{(\mathrm{Si}-\mathrm{CH} 2 \mathrm{R})}=1204 \mathrm{~cm}^{-1}, v_{(\mathrm{Si}-\mathrm{CH} 3)}=1267 \mathrm{~cm}^{-1}$, $v_{(\mathrm{COO}-)_{\text {symm }}}=1316 \mathrm{~cm}^{-1}, \quad \delta_{(\mathrm{C}-\mathrm{H}) \text { symm }}=1422 \mathrm{~cm}^{-1}$, $\delta_{(\mathrm{C}-\mathrm{H}) \text { asymm }}=1436 \quad \mathrm{~cm}^{-1}, \quad \delta_{(\mathrm{C}-\mathrm{H}) \text { symm }}=1470 \quad \mathrm{~cm}^{-1}$, $v_{\text {(COO-)asymm }}=1588 \mathrm{~cm}^{-1}, v_{(\mathrm{C}-\mathrm{H}) \text { symm }}=2849 \mathrm{~cm}^{-1}$,

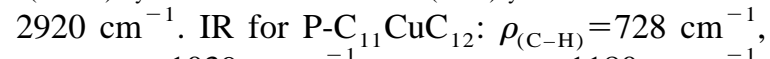
$v_{(\mathrm{Si}-\mathrm{O}-\mathrm{Si})}=1039 \mathrm{~cm}^{-1}, \quad v_{(\mathrm{Si}-\mathrm{CH} 2 \mathrm{R})}=1180 \quad \mathrm{~cm}^{-1}$, $v_{(\mathrm{Si}-\mathrm{CH} 3)}=1267 \quad \mathrm{~cm}^{-1}, \quad v_{(\mathrm{COO}-)_{\mathrm{symm}}}=1315 \quad \mathrm{~cm}^{-1}$, $\delta_{(\mathrm{C}-\mathrm{H}) \mathrm{symm}}=1416 \mathrm{~cm}^{-1}, \quad \delta_{(\mathrm{C}-\mathrm{H}) \text { asymm }}=1455 \mathrm{~cm}^{-1}$, $\delta_{(\mathrm{C}-\mathrm{H}) \text { symm }}=1470 \mathrm{~cm}^{-1}, \quad v_{(\mathrm{COO}-\text { )asymm }}=1588 \mathrm{~cm}^{-1}$, $v_{\text {(C-H)symm }}=2849 \mathrm{~cm}^{-1}, 2917 \mathrm{~cm}^{-1}$. Elemental analysis (EA) for $\mathrm{P}_{-} \mathrm{C}_{11} \mathrm{CuC}_{18}$ is $\mathrm{C} 65.01 \%, \mathrm{H} 10.81 \%$ while that for $\mathrm{P}_{-} \mathrm{C}_{11} \mathrm{CuC}_{12}$ is $\mathrm{C} 60.75 \%, \mathrm{H} 9.79 \%$.

\subsection{Capillary column preparation}

Deactivated fused-silica capillaries (250 $\mu \mathrm{m}$ I.D.) (Restek, Bellefonte, PA, USA) were first rinsed with methanol and dichloromethane (5 $\mathrm{ml}$ each) sequentially. The capillary column preparation with film thickness of $1.9 \mu \mathrm{m}$ using a static procedure was performed according to Ref. [11], while that with a dynamic procedure was as in Ref. [13]. For each procedure, a solution of $3 \%$ prepared from $0.15 \mathrm{~g}$ linear metallomesogenic polymer in $5 \mathrm{ml}$ dichloromethane (which also contained benzoyl peroxide, the amount being $3 \%$, w/w, of the linear polymer) was used to fill the capillary.

\section{Results and discussion}

In this work, 10-undecenoic acid acting as spacer was reacted with the poly(methylhydrosiloxane). Metallomesogenic monomers, sodium stearate and sodium laurate, respectively, were then introduced into the respective polymer. The synthetic procedures are illustrated as Fig. 1. The resultant metallomesogenic polymers, $\mathrm{P}-\mathrm{C}_{11} \mathrm{CuC}_{18}$ and $\mathrm{P}-\mathrm{C}_{11} \mathrm{CuC}_{12}$ were employed as the stationary phases for the separation of phthalate esters. To be considered satisfactory for use in wall-coated open tubular capillary columns, stationary phases must meet certain criteria. These requirements are thermal stability, physical stability and cross-linking. The achieved properties were investigated as follows.

(1)

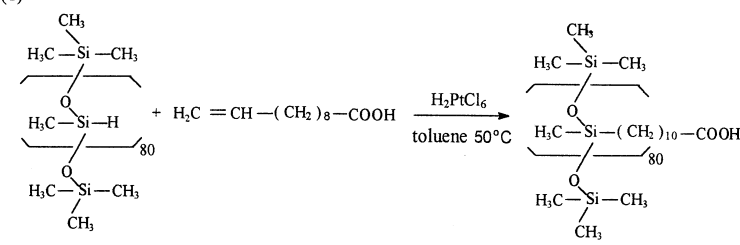

(2)

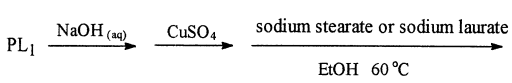

$\mathbf{P L}_{1}$

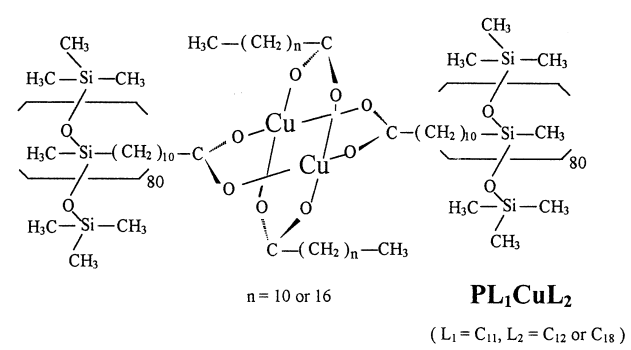

Fig. 1. Synthetic procedures for the metallomesogenic polymers. 


\subsection{Characterization}

The liquid crystal properties of the mesogenic substances were characterized via the techniques of polarized light microscopy and calorimetric investigation. Phase transitions for $\mathrm{P}_{-11} \mathrm{CuC}_{18}$ at 77.9 and $93.7^{\circ} \mathrm{C}$ with $\Delta H$ of 40.0 and $44.2 \mathrm{~J} \mathrm{~g}^{-1}$ on the first heating cycle were indicated (Fig. 2A). If the sample was then cooled from $250^{\circ} \mathrm{C}$, we obtained two exothermic peaks at 84.5 and $36.6^{\circ} \mathrm{C}$ with $\Delta H$ of 54.9 and $25.0 \mathrm{~J} \mathrm{~g}^{-1}$, respectively (Fig. 2B). On the second heating, two endothermic peaks at 44.4 and $104.0^{\circ} \mathrm{C}$ with $\Delta H$ of 25.0 and $64.0 \mathrm{~J} \mathrm{~g}^{-1}$, respectively, were found (Fig. 2C). We found two exothermic peaks once more at 83.0 and $37.7^{\circ} \mathrm{C}$ with $\Delta H$ of 53.6 and $29.8 \mathrm{~J} \mathrm{~g}^{-1}$, respectively, on the second cooling process (Fig. 2D). For $\mathrm{P}_{-} \mathrm{C}_{11} \mathrm{CuC}_{12}$, only one endothermic peak at $81.0^{\circ} \mathrm{C}$ with $\Delta H$ of $61.3 \mathrm{~J} \mathrm{~g} \mathrm{~g}^{-1}$ was shown at first heating and one exothermic peak was found at $51.5^{\circ} \mathrm{C}$ with $\Delta H$ of $63.9 \mathrm{~J} \mathrm{~g}^{-1}$ on the cooling process. There were two endothermic peaks at 81.6 and $98.4^{\circ} \mathrm{C}$ with $\Delta H$ of 67.0 and $5.3 \mathrm{~J} \mathrm{~g}^{-1}$, respectively, on the second heating. The DSC curves for these cycles are shown in Fig. 3. The results obtained, together with those of the metallomesogenic monomers from DSC measurements are summarized in Table 1. All DSC profiles display at $10^{\circ} \mathrm{C} \min ^{-1}$. The DSC data showed a larger enthalpy change for the polymer than for the monomer from the crystalline state to the discotic lamellar phase, except for $\mathrm{P}_{-} \mathrm{C}_{11} \mathrm{CuC}_{18}$. The lower phase transition temperature of $\mathrm{C}_{18}$ analogues compared with $\mathrm{C}_{12}$ analogues indicates an easier rearrangement of the molecule into an ordered structure. Among the polymers studied, $\mathrm{P}-\mathrm{C}_{11} \mathrm{CuC}_{18}$ appeared to cover a widest range of the $\mathrm{D}_{\mathrm{L}}$ liquid crystal phase $\left(60^{\circ} \mathrm{C}\right)$, $\mathrm{P}-\mathrm{C}_{15} \mathrm{CuC}_{18}$ is next $\left(45^{\circ} \mathrm{C}\right)$ and $\mathrm{P}_{-} \mathrm{C}_{11} \mathrm{CuC}_{12}$ is narrowest, only $17^{\circ} \mathrm{C}$. In other words, the temperature range seems dependent on the different chain lengths of the mix-ligand. A possible explanation is

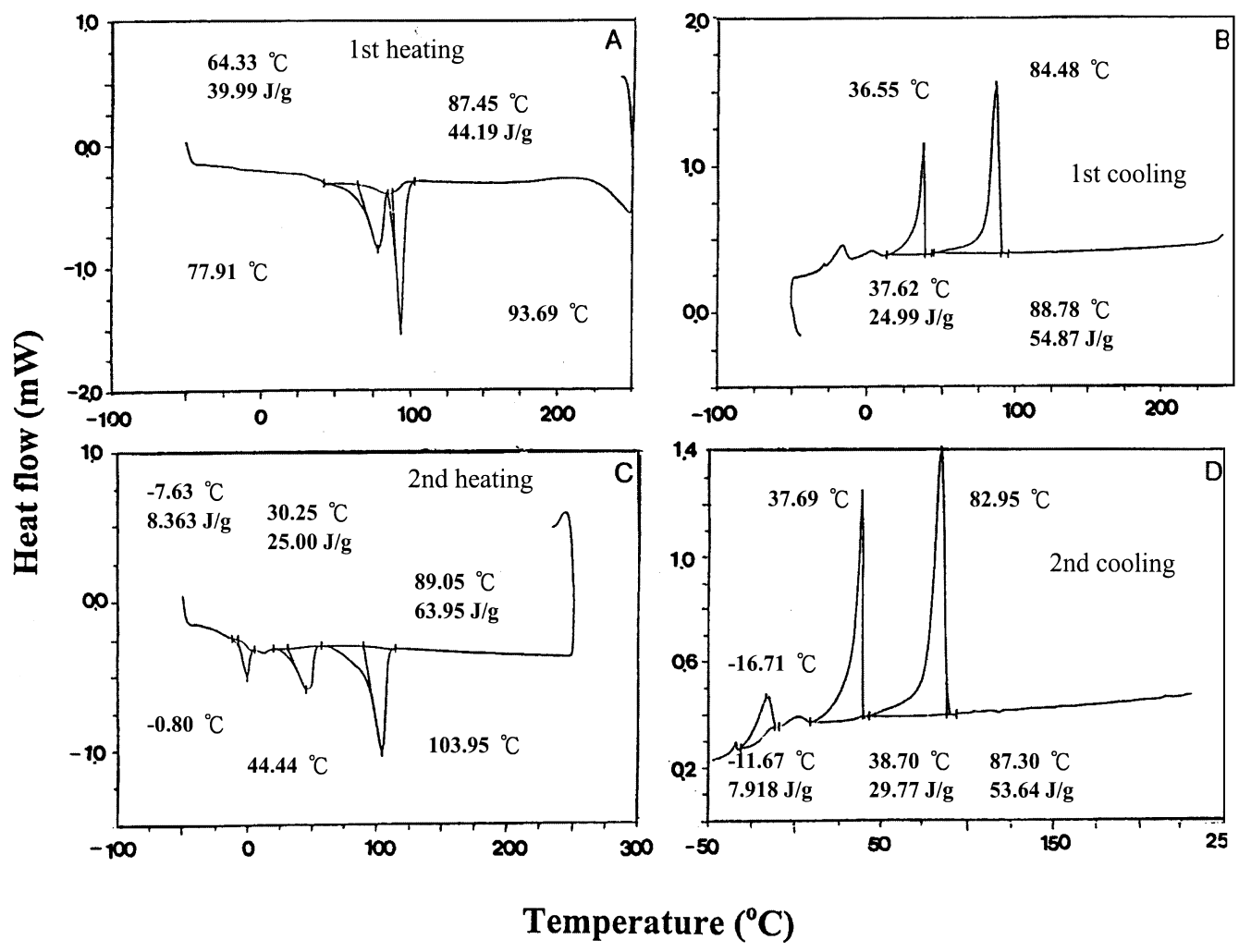

Fig. 2. The differential scanning calorimetry thermograms of siloxane polymer containing copper stearate $\left(\mathrm{P}-\mathrm{C}_{11} \mathrm{CuC} \mathrm{C}_{18}\right)$. $(\mathrm{A})$ First heating; (B) first cooling; (C) second heating; (D) second cooling. 


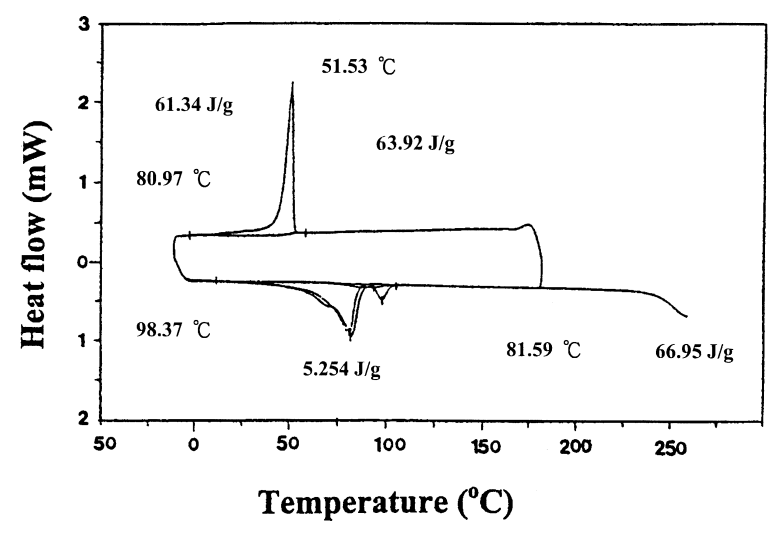

Fig. 3. The differential scanning calorimetry thermograms of siloxane polymer containing copper laurate $\left(\mathrm{P}-\mathrm{C}_{11} \mathrm{CuC}_{12}\right)$ including the cycles of first heating, first cooling and second heating.

that some chain segments are able to associate relatively quickly but do not contribute significantly to network formation. When the metallomesogen is cooled to room temperature after first heating, all exhibited the temperature range for the $\mathrm{D}_{\mathrm{ho}}$ phase. But both $\mathrm{CuC}_{12}$ and $\mathrm{P}_{-} \mathrm{C}_{11} \mathrm{CuC}_{12}$ got only one liquid crystal phase and no $\mathrm{D}_{\mathrm{L}}$ phase was indicated. Thermal gravimetric analysis (TGA) showed that the temperature for the significant weight loss was higher than $260^{\circ} \mathrm{C}$ as shown in Fig. 4. The morphological observations under polarized light microscopy at different temperatures were consistent with those described in the thermal analysis. Fig. 5 shows the morphologies of the $\mathrm{D}_{\mathrm{L}}$ and $\mathrm{D}_{\mathrm{ho}}$ phases of $\mathrm{P}-\mathrm{C}_{11} \mathrm{CuC}_{18}$.

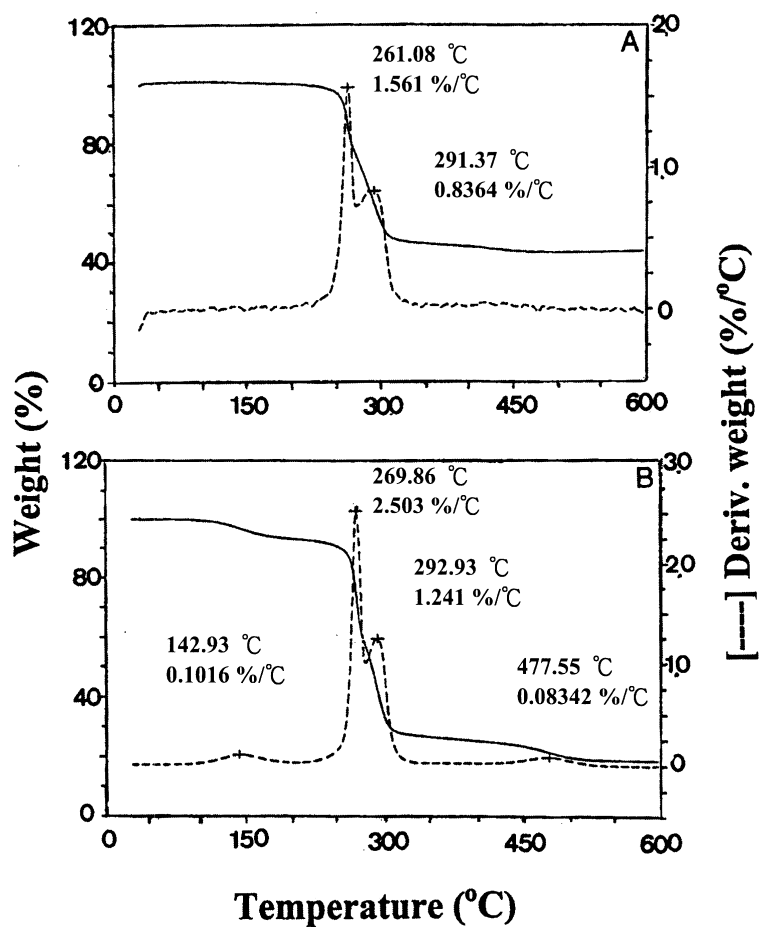

Fig. 4. The thermogravimetric analysis of $\mathrm{P}_{-} \mathrm{C}_{11} \mathrm{CuC}_{18}$ (A) and $\mathrm{P}-\mathrm{C}_{11} \mathrm{CuC}_{12}$ (B).

\subsection{Column performance evaluation}

In this study, the prepared columns were evaluated for their performance in the GC separation of phthalate esters. Fig. 6 shows the structures of the phthalate esters studied. Due to the widest range of the liquid crystal phase among the polymer prepared,

Table 1

Phase transitions of the metallomesogenic polymers ${ }^{\mathrm{a}}$

\begin{tabular}{lll}
\hline Polymer & \multicolumn{2}{l}{ Phase transitions $\left({ }^{\circ} \mathrm{C}\right)$ and corresponding enthalpy changes $\left(\mathrm{J} \mathrm{g}^{-1}\right)$} \\
\cline { 2 - 3 } & Heating & Cooling \\
\hline $\mathrm{CuC}_{18}{ }^{\mathrm{b}, \mathrm{c}}$ & $\mathrm{k}-54.0(23.0)-\mathrm{D}_{\mathrm{L}}-125.0(37.4)-\mathrm{D}_{\mathrm{ho}}-200-\mathrm{i}$ & $\mathrm{i}-200-\mathrm{D}_{\mathrm{ho}}-107.6(52.6)-\mathrm{D}_{\mathrm{L}}-41.1(13.5)-\mathrm{k}$ \\
$\mathrm{CuC}_{12}{ }_{\mathrm{b}}$ & $\mathrm{k}-94.0(21.9)-\mathrm{D}_{\mathrm{L}}-118.3(83.9)-\mathrm{D}_{\mathrm{ho}}-200-\mathrm{i}$ & $\mathrm{i}-200-\mathrm{D}_{\mathrm{ho}}-71.3(102.9)-\mathrm{k}$ \\
$\mathrm{P}_{\mathrm{C}}{ }_{15} \mathrm{CuC}_{18}{ }^{\mathrm{c}}$ & $\mathrm{k}-50.7(36.4)-\mathrm{D}_{\mathrm{L}}-95(4.4)-\mathrm{D}_{\mathrm{ho}}-200-\mathrm{i}$ & $\mathrm{i}-200-\mathrm{D}_{\mathrm{ho}}-77.5(5.8)-\mathrm{D}_{\mathrm{L}}-33.2(43.7)-\mathrm{k}$ \\
$\mathrm{P}_{-} \mathrm{C}_{11} \mathrm{CuC}_{18}$ & $\mathrm{k}-44.4(25.0)-\mathrm{D}_{\mathrm{L}}-104(64.0)-\mathrm{D}_{\mathrm{ho}}-200-\mathrm{i}$ & $\mathrm{i}-200-\mathrm{D}_{\mathrm{ho}}-84.5(54.9)-\mathrm{D}_{\mathrm{L}}-36.6(25.0)-\mathrm{k}$ \\
$\mathrm{P}_{-C_{11}} \mathrm{CuC}_{12}$ & $\mathrm{k}-81.6(67.0)-\mathrm{D}_{\mathrm{L}}-98.4(5.3)-\mathrm{D}_{\mathrm{ho}}-200-\mathrm{i}$ & $\mathrm{i}-200-\mathrm{D}_{\mathrm{ho}}-51.5(63.9)-\mathrm{k}$ \\
\hline
\end{tabular}

\footnotetext{
${ }^{\mathrm{a}}$ Data are from second heating and first cooling scans. $\mathrm{k}$ : Crystalline, $\mathrm{D}_{\mathrm{L}}$ : discotic lamellar phase, $\mathrm{D}_{\mathrm{ho}}$ : ordered hexagonal columnar discotic mesophase, i: isotropic phase.

${ }^{\mathrm{b}}$ Metallomesogenic monomer.

${ }^{\mathrm{c}}$ Data from Ref. [13].
} 
A

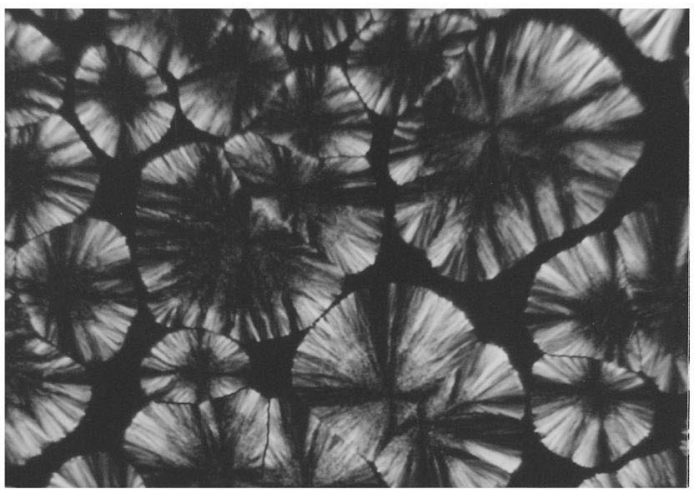

C

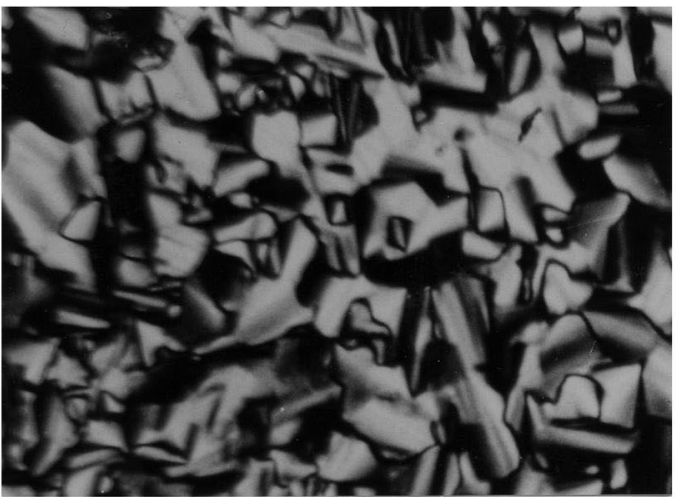

B

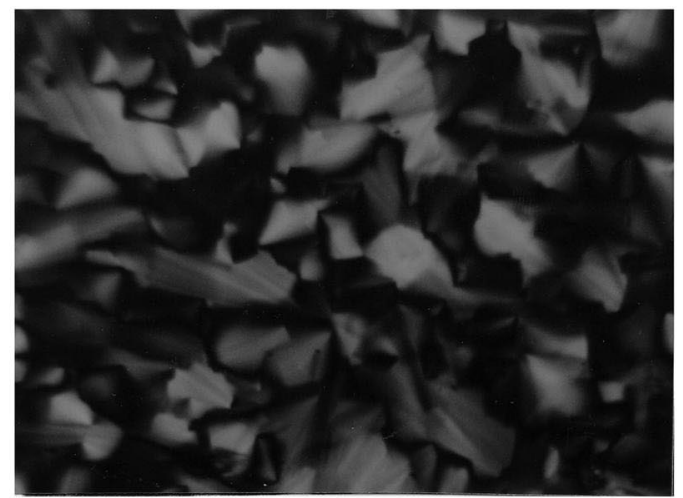

D

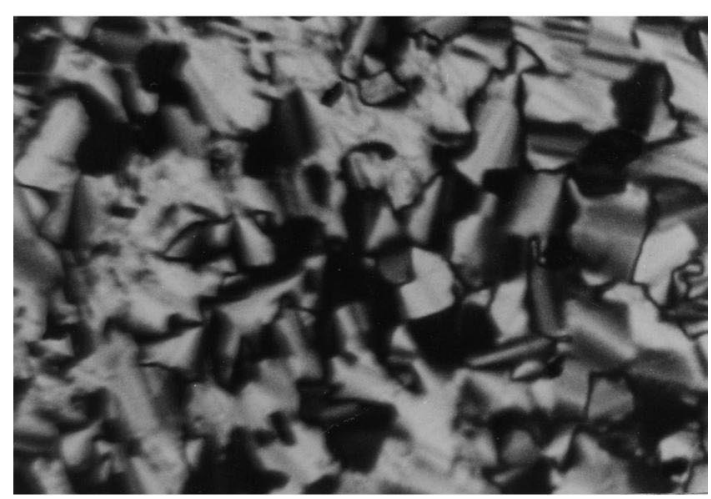

Fig. 5. The optical polarizing micrographs of copper stearate $\left(\mathrm{CuC}_{18}\right)$ and $\mathrm{P}-\mathrm{C}_{11} \mathrm{CuC}_{18} \cdot \mathrm{CuC}_{18}:(\mathrm{A}) \mathrm{D}_{\mathrm{L}}$ phase at $83^{\circ} \mathrm{C}$; (B) $\mathrm{D}_{\text {ho }}$ phase at $142^{\circ} \mathrm{C} . \mathrm{P}^{-\mathrm{C}_{11}} \mathrm{CuC}_{18}:(\mathrm{C}) \mathrm{D}_{\mathrm{L}}$ phase at $79^{\circ} \mathrm{C}$; (D) $\mathrm{D}_{\text {ho }}$ phase at $137^{\circ} \mathrm{C}$.

$\mathrm{P}-\mathrm{C}_{11} \mathrm{CuC}_{18}$ was therefore chosen as the first priority stationary phase for the separation of phthalates.

\subsubsection{Optimization of capillary GC procedure}

In a preliminary test, at the conditions of injection temperature of $350^{\circ} \mathrm{C}$, split ratio of $1 / 40$ and inlet pressure of $10 \mathrm{kPa}$, namely linear velocity being 5.9 $\mathrm{cm} \mathrm{s}^{-1}$ were found to be the best conditions for the separation of phthalate esters. Because of the wide range of boiling points for the compounds tested $\left(220-413^{\circ} \mathrm{C}\right)$, it is not easy to separate all of them isothermally within a reasonable time. For investigating the column efficiency, isothermal conditions from 95 to $110^{\circ} \mathrm{C}$ were studied for the five faster eluted phthalates. The conditions from 150 to $180^{\circ} \mathrm{C}$ were studied for the other seven more slowly eluting phthalates. The chromatograms shown in Fig. 7A and B demonstrate good selectivity of the new stationary phase toward the phthalate substitutents, even for the positional isomers. The separation efficiencies at 110 and $170^{\circ} \mathrm{C}$ are summarized in Table 2. Most results are satisfactory. However, the results suggest that the temperature program was needed for the separation of all phthalates in a single run.

Fig. 8A and B show the dependence of $\log k^{\prime}$ of phthalate esters against reciprocal absolute temperature of the polymeric metallomesogens. Changes in the slope around $104^{\circ} \mathrm{C}$ would be indicative of phase changes in the column but no distinct inflection point was indicated (Fig. 8A). The closely parallel lines indicate a rather similar solubility among the tested solute in the mesogenic phases. Meanwhile no significant variation of the solute solubility between $D_{L}$ and $D_{h o}$ phases for each solute exhibited. The mentioned properties resulted in no strong break in 


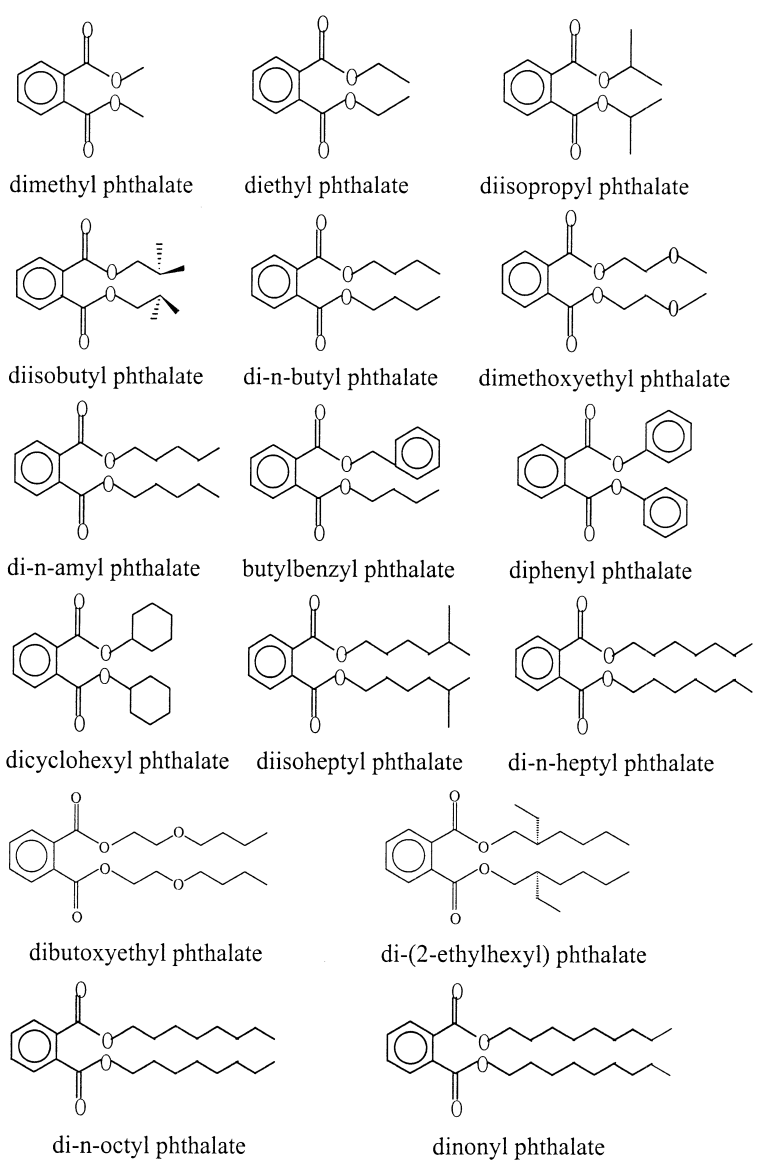

Fig. 6. Structures of the studied phthalate esters.

this plot. Additionally only one liquid crystalline phase $\left(D_{h o}\right)$ existed over the temperature range studied in Fig. 8B, so a linear line was indicated.

Under the conditions previously selected, several assays were performed to find a temperature program that provided the separation of the phthalate esters. One of the best options was the following program: $110^{\circ} \mathrm{C}$ for $7 \mathrm{~min}$, to $160^{\circ} \mathrm{C}$ at $5^{\circ} \mathrm{C} \mathrm{min}^{-1}$ and held 10 min, then to $200^{\circ} \mathrm{C}$ at $7^{\circ} \mathrm{C} \mathrm{min}{ }^{-1}$. The chromatogram at this optimum condition is shown in Fig. 9, in which a complete separation of all compounds is demonstrated.

\subsection{Mechanism for the separation}

The factors responsible for the elution order of the phthalate esters were considered to be as follows.

\subsubsection{Polarity interaction}

In this work, the separation order was dimethyl phthalate $>$ diethyl phthalate $>$ diisopropyl phthalate $>$ diisobutyl phthalate $>$ di- $n$-butyl phthalate $>$ dimethoxyethyl phthalate $>$ di- $n$-amyl phthalate $>$ butylbenzyl phthalate (1)>di-(2-ethylhexyl) phthalate (2)>dicyclohexyl phthalate (3)>dibutoxyethyl phthalate (4) $>$ di- $n$-octyl phthalate $>$ dinonyl phthalate $>$ diphenyl phthalate. With US Environmental Protection Agency (EPA) method 8060 for the separation of phthalate esters using Rtx-5 (5\% diphenyl-95\% dimethyl polysiloxane from Restek) [24], a significant difference for the separation order was $1>4>3>2$ for the noted compounds. While using a more polar stationary phase, Rtx-50 (50\% phenyl-50\% methyl polysiloxane), not only a nonresolved peak for 4 and 3 but also a significant reverse order for the noted compounds, $4 \approx 3>2>1$ was found. It was obvious that the polarity of the new stationary phase might be intermediate among them.

\subsubsection{Ligand exchange}

Phthalates with $\pi$ electrons in the benzene ring could form complexes with the stationary phase having an empty orbital of the central metal atom. Diphenyl phthalate has most $\pi$ electrons among the compounds tested, thus the retention is strongest. The presence of longer alkyl groups might lead one to expect a greater electron density on the oxygen atom. Two extra oxygen atoms were present for the dibutoxyethyl phthalate and dimethoxyethyl phthalate. The coordinating bond with the copper atom of the stationary phase for the mentioned compounds would be stronger than any other compounds. Thus they were retained longer than other substituents with similar alkyl length. We note also that dibutoxyethyl phthalate (b.p. $210^{\circ} \mathrm{C}$ ) is farther from the predicted time than dimethoxyethyl phthalate (b.p. $\left.230^{\circ} \mathrm{C}\right)$.

\subsubsection{Molecular shape}

Solutes most similar to the disk-type ordered environment would interact more strongly with the stationary phase. Therefore dicyclohexyl phthalate was eluted after di-(2-ethylhexyl) phthalate. This might be due to the fact that the former is inserted more easily into the ordered liquid crystal structure. 


\section{A}

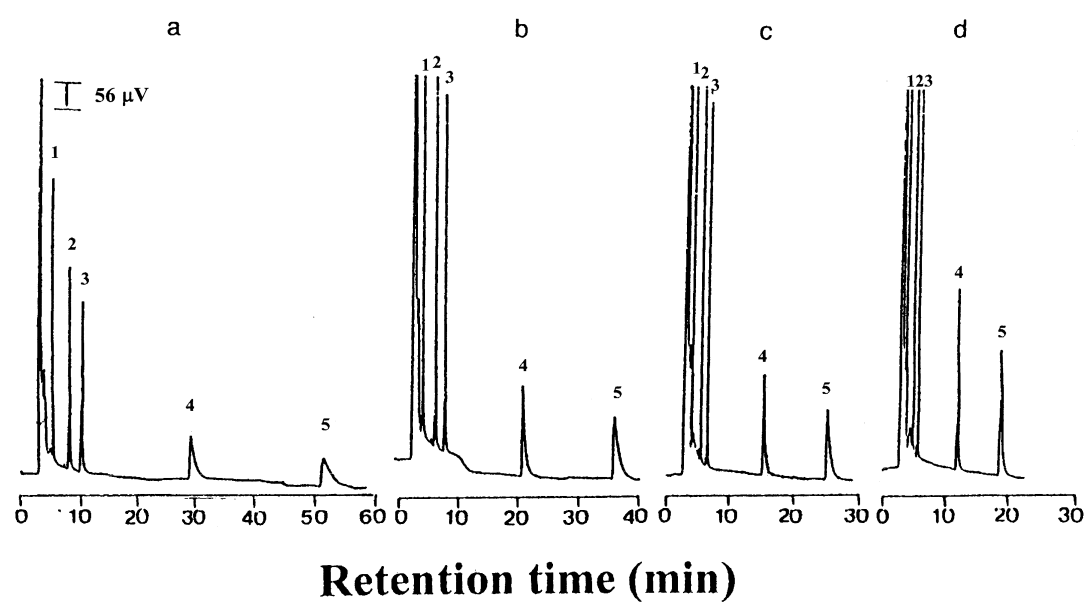

B
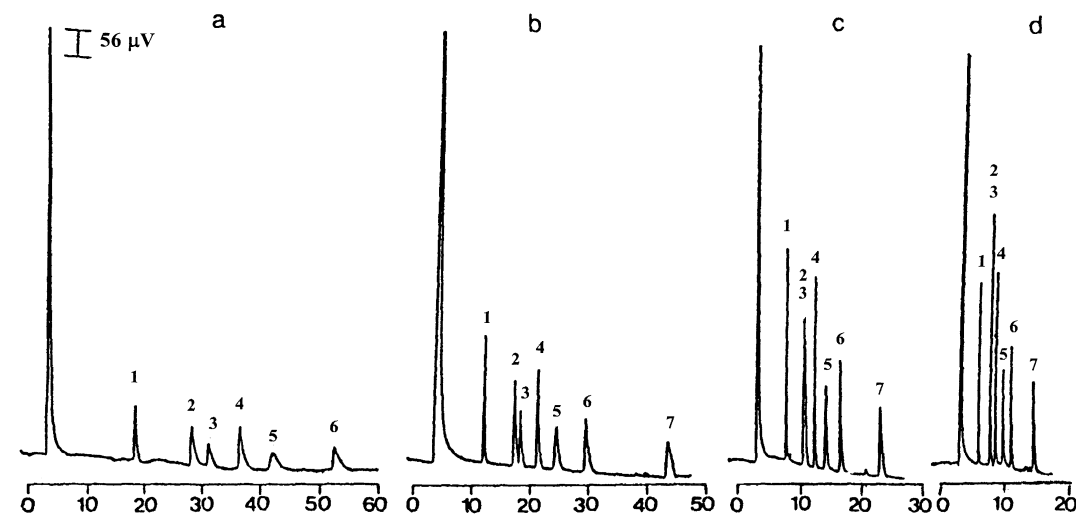

\section{Retention time (min)}

Fig. 7. The separation of phthalate esters at isothermal conditions. Stationary phase: wall coated with P-C $\mathrm{C}_{11} \mathrm{CuC}_{18}(15 \mathrm{~m} \times 250 \mu \mathrm{m}$ I.D. $)$ (static coating, film thickness $1.9 \mu \mathrm{m}$ ), injection volume: $1 \mu \mathrm{l}$, injector temperature: $350^{\circ} \mathrm{C}$, carrier gas: nitrogen, split ratio: $1 / 40$, inlet pressure: $10 \mathrm{kPa}$, sample concentration: $320 \mu \mathrm{g} \mathrm{ml}{ }^{-1}$. Column temperature: $(\mathrm{A}) \mathrm{a}=95^{\circ} \mathrm{C}, \mathrm{b}=100^{\circ} \mathrm{C}, \mathrm{c}=105^{\circ} \mathrm{C}, \mathrm{d}=110^{\circ} \mathrm{C} ;(\mathrm{B}) \mathrm{a}=150^{\circ} \mathrm{C}$, $\mathrm{b}=160^{\circ} \mathrm{C}, \mathrm{c}=170^{\circ} \mathrm{C}, \mathrm{d}=180^{\circ} \mathrm{C}$. Peaks: (A) $1=$ dimethyl phthalate, $2=$ diethyl phthalate, $3=$ diisopropyl phthalate, $4=$ diisobutyl phthalate, $5=$ di- $n$-octyl phthalate; (B) $1=$ butylbenzyl phthalate, $2=$ di-(2-ethylhexyl) phthalate, $3=$ dicyclohexyl phthalate, $4=$ dibutoxyethyl phthalate, $5=$ di- $n$-octyl phthalate, $6=$ dinonyl phthalate, $7=$ diphenyl phthalate.

\subsection{Linear calibration range}

Detector response was linearly correlated with the sample concentration injected over a range of 10$625 \mu \mathrm{g} \mathrm{ml}^{-1}$ for all the compounds studied. The calibration graphs of peak area against the quantity of each analyte are listed in Table 3 . The correlation coefficients for all the calibration graphs were between 0.9999 and 0.9979. The three times standard deviation of seven measurements of the lowest peak that could be detected is less than $30 \mathrm{pg}$ for $1 \mu \mathrm{l}$ injection except for dimethoxyethyl phthalate. The established system with high reproducibility and low detection limit (Table 3) is highly promising when applied to the real sample. 
Table 2

Separation efficiency of the fused-silica capillary column with wall-coated metallomesogenic polymer ${ }^{\mathrm{a}}$

\begin{tabular}{lccc}
\hline Analyte & $\begin{array}{l}\text { Retention time } \\
(\mathrm{min})\end{array}$ & $\begin{array}{l}N \\
\left.\text { (plates m }^{-1}\right)\end{array}$ & $\begin{array}{l}\text { HETP } \\
(\mathrm{mm})\end{array}$ \\
\hline Dimethyl phthalate $^{\mathrm{b}}$ & 3.88 & 1251 & 0.79 \\
Diethyl phthalate $^{\mathrm{b}}$ & 4.99 & 1137 & 0.88 \\
Diisopropyl phthalate $^{\mathrm{b}}$ & 5.81 & 1335 & 0.75 \\
Diisobutyl phthalate $^{\mathrm{b}}$ & 12.40 & 885 & 1.13 \\
Di- $n$-butyl phthalate $^{\mathrm{b}}$ & 19.50 & 815 & 1.23 \\
Butylbenzyl phthalate $^{\mathrm{c}}$ & 9.48 & 987 & 1.01 \\
Di-(2-ethylhexyl) phthalate $^{\mathrm{c}}$ & 12.43 & 889 & 1.13 \\
Dicyclohexyl phthalate $^{\mathrm{c}}$ & 12.74 & 1000 & \\
Dibutoxyethyl phthalate $^{\mathrm{c}}$ & 14.22 & 1353 & \\
Di- $n$-octyl phthalate $^{\mathrm{c}}$ & 16.26 & 620 & 0.74 \\
Dinonyl phthalate $^{\mathrm{c}}$ & 18.72 & 1277 & 1.61 \\
Diphenyl phthalate $^{\mathrm{c}}$ & 25.70 & 914 & 0.78 \\
\hline
\end{tabular}

$N$, Number of theoretical plates; HETP, height equivalent to theoretical plate.

${ }^{a}$ Stationary phase: wall coated with $\mathrm{P}_{-} \mathrm{C}_{11} \mathrm{CuC}_{18}(15 \mathrm{~m} \times 250 \mu \mathrm{m}$ I.D. $)$; injection volume: $1 \mu \mathrm{l}$; injector temperature: $350^{\circ} \mathrm{C}$; inlet pressure: $10 \mathrm{kPa}$; split ratio: 1/40; carrier gas: nitrogen; sample concentration: $320 \mu \mathrm{g} \mathrm{ml}^{-1}$.

${ }^{\mathrm{b}}$ Column temperature: $110^{\circ} \mathrm{C}$.

${ }^{\mathrm{c}}$ Column temperature: $170^{\circ} \mathrm{C}$.

\subsection{Comparison of $P-C_{11} C u C_{12}$ and $P-C_{11} C u C_{18}$} columns

The effect of lauric acid and stearic acid, respectively, as the ligands of the metallomesogenic polymer on the separation of phthalate esters was also investigated. In this work, a dynamic coating procedure [13] was used for the preparation of both capillary columns $(10 \mathrm{~m} \times 250 \mu \mathrm{m}$ I.D. $)$. Meanwhile a shorter column $(10 \mathrm{~m})$ than the above mentioned column $(15 \mathrm{~m})$ was employed. With the column temperature of $110^{\circ} \mathrm{C}$ (hold $2 \mathrm{~min}$ ) to $195^{\circ} \mathrm{C}$ (hold 10

Table 3

Summary for the determination of phthalate esters with the wall coated $\mathrm{P}_{-} \mathrm{C}_{11} \mathrm{CuC}_{18}$ capillary column ${ }^{\mathrm{a}}$

\begin{tabular}{lcll}
\hline Analyte & $\begin{array}{l}\text { Retention time } \\
(\mathrm{min})\end{array}$ & $\begin{array}{l}\text { Linear equation }^{\mathrm{b}} \\
\left(y: \text { peak area, } \mu \mathrm{V} \mathrm{s} ; x \text { : concentration, } \mu \mathrm{g} \mathrm{m}^{-1}\right)\end{array}$ & $\begin{array}{l}\text { Detection limit } \\
(\mathrm{pg})\end{array}$ \\
\hline Dimethyl phthalate & $6.57 \pm 0.04^{\mathrm{c}}$ & $y=14.37 x+60.43(0.9994)^{\mathrm{d}}$ & 18.24 \\
Diethyl phthalate & $9.07 \pm 0.07$ & $y=15.34 x+92.40(0.9993)$ & 24.33 \\
Diisopropyl phthalate & $10.35 \pm 0.08$ & $y=16.66 x+100.80(0.9994)$ & 16.56 \\
Diisobutyl phthalate & $15.19 \pm 0.05$ & $y=16.52 x+194.87(0.9994)$ & 15.29 \\
Di- $n$-butyl phthalate & $17.32 \pm 0.11$ & $y=15.87 x+188.70(0.9993)$ & 20.87 \\
Dimethoxyethyl phthalate & $19.21 \pm 0.03$ & $y=11.02 x-126.96(0.9979)$ & 40.94 \\
Di- $n$-amyl phthalate & $21.12 \pm 0.03$ & $y=15.67 x+217.38(0.9991)$ & 10.17 \\
Butylbenzyl phthalate & $27.00 \pm 0.10$ & $y=14.19 x+119.76(0.9987)$ & 24.48 \\
Di-(2-ethylhexyl) phthalate & $31.15 \pm 0.03$ & $y=14.79 x+378.75(0.9999)$ & 16.02 \\
Dicyclohexyl phthalate & $31.67 \pm 0.03$ & $y=8.96 x+35.89(0.9994)$ & 28.16 \\
Dibutoxyethyl phthalate & $32.76 \pm 0.03$ & $y=15.37 x+665.67(0.9998)$ & 18.12 \\
Di- $n$-octyl phthalate & $33.88 \pm 0.06$ & $y=10.05 x+454.98(0.9995)$ & 14.38 \\
Dinonyl phthalate & $34.86 \pm 0.03$ & $y=13.50 x+341.65(0.9992)$ & 16.88 \\
Diphenyl phthalate & $37.05 \pm 0.04$ & $y=13.50 x+395.15(0.9993)$ & 17.63 \\
\hline
\end{tabular}

\footnotetext{
${ }^{\mathrm{a}}$ Conditions as in Fig. 9.

${ }^{\mathrm{b}}$ Linear range studied: $10-625 \mu \mathrm{g} \mathrm{ml}{ }^{-1}$.

${ }^{\mathrm{c}}$ Average of eight measurements.

${ }^{\mathrm{d}}$ Correlation coefficient.
} 

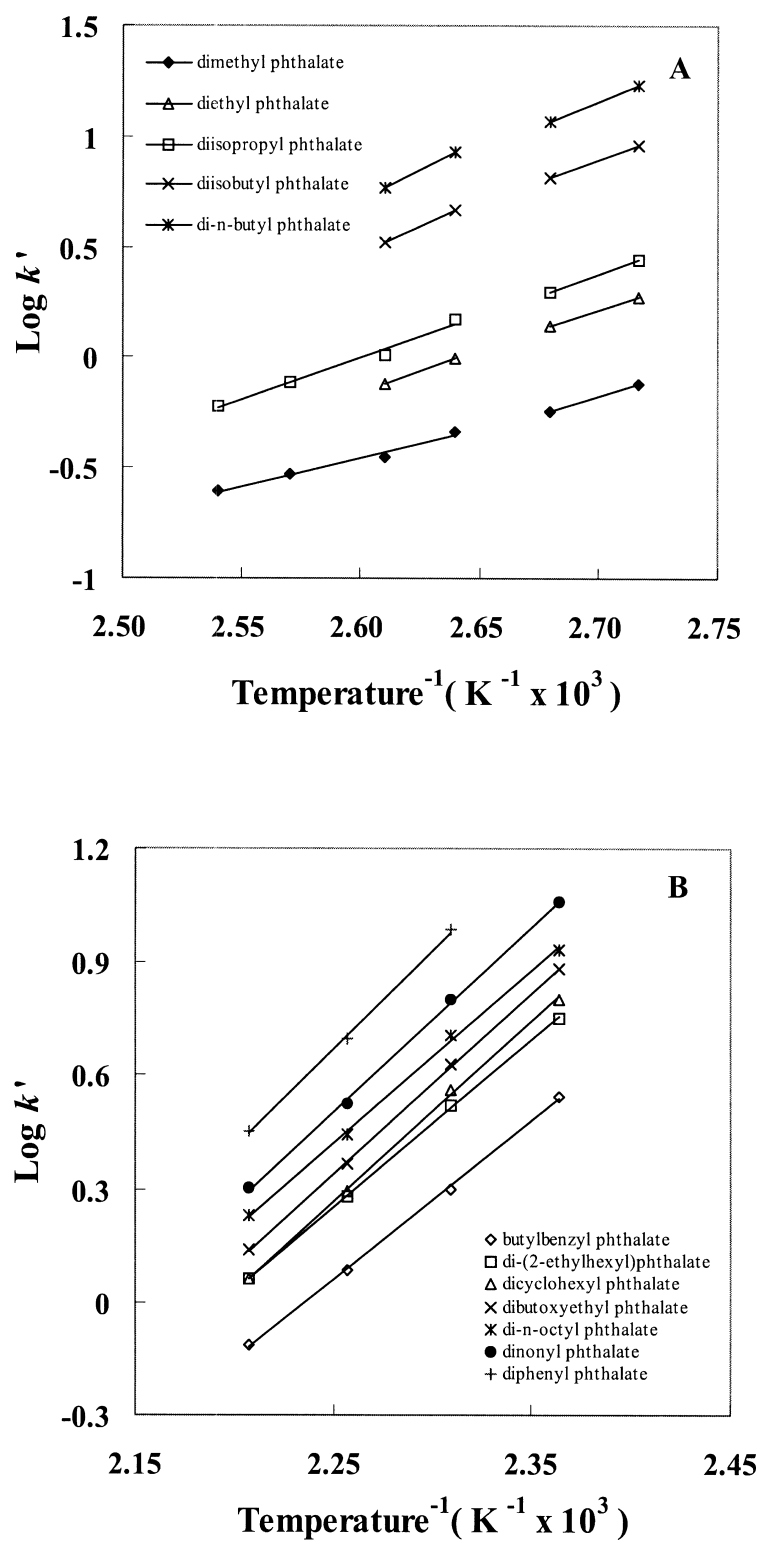

Fig. 8. Van't Hoff plots of phthalate esters. Conditions as in Fig. 7.

min) then to $215^{\circ} \mathrm{C}$ at the rate of $3^{\circ} \mathrm{C} \mathrm{min}{ }^{-1}$ and inlet pressure of $15 \mathrm{kPa}$ (hold $30 \mathrm{~min}$ ) to $10 \mathrm{kPa}$ at -3 $\mathrm{kPa} \min ^{-1}$, a complete separation of 16 phthalate esters was achieved, except di-(2-ethylhexyl) phthalate and dibutoxyethyl phthalate was non-baseline resolved (Fig. 10). While at the column temperature of $110^{\circ} \mathrm{C}$ (hold $2 \mathrm{~min}$ ) to $190^{\circ} \mathrm{C}$ (hold $10 \mathrm{~min}$ ) at the

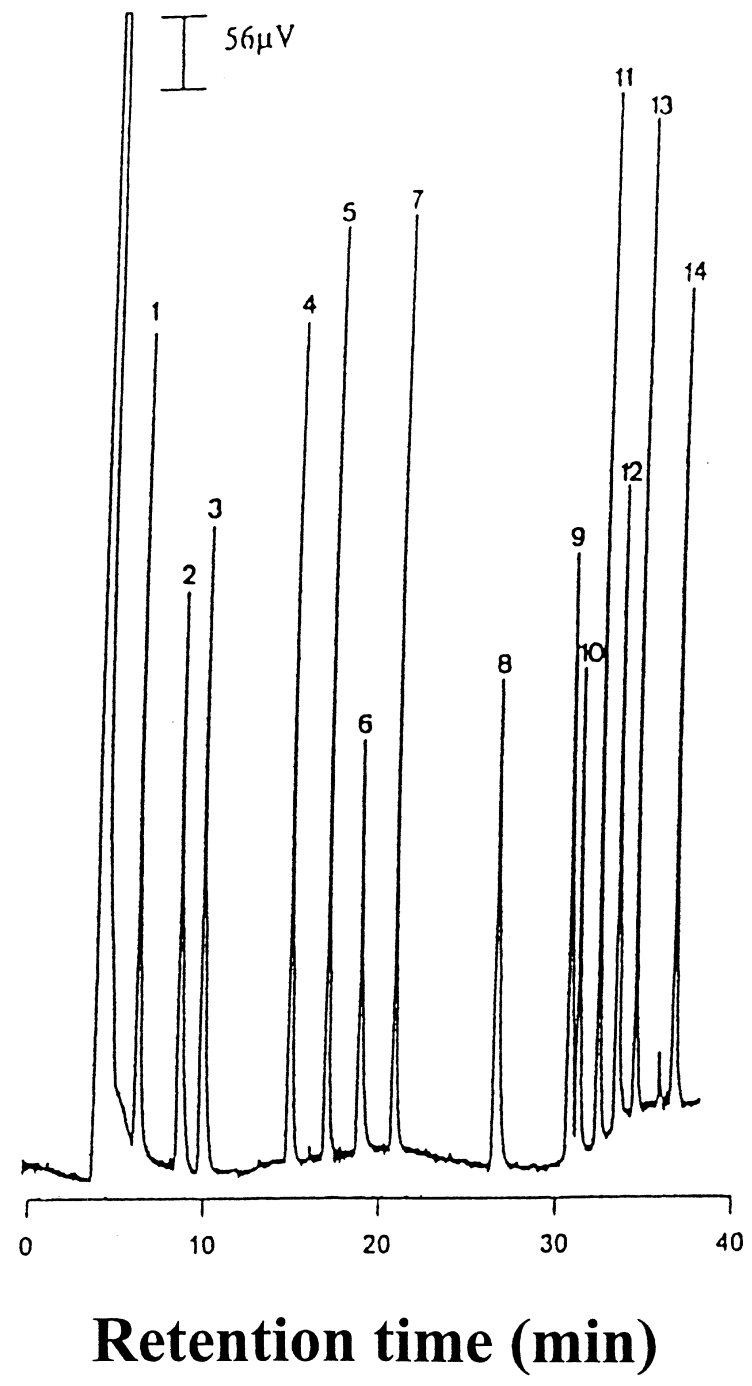

Fig. 9. Chromatogram for the separation of phthalate esters at temperature program condition with capillary column via static coating $\mathrm{P}-\mathrm{C}_{11} \mathrm{CuC}_{18}$. Conditions as in Fig. 7, except the column temperature is $110^{\circ} \mathrm{C}$ (hold $7 \mathrm{~min}$ ) to $160^{\circ} \mathrm{C}$ (hold $10 \mathrm{~min}$ ) at $5^{\circ} \mathrm{C}$ $\mathrm{min}^{-1}$ then to $200^{\circ} \mathrm{C}$ at $7^{\circ} \mathrm{C} \mathrm{min}^{-1}$. Peaks: $1=$ dimethyl phthalate, $2=$ diethyl phthalate, $3=$ diisopropyl phthalate, $4=$ diisobutyl phthalate, $5=$ di- $n$-butyl phthalate, $6=$ dimethoxyethyl phthalate, $7=$ di $-n$-amyl phthalate, $8=$ butylbenzyl phthalate, $9=$ di $-(2-$ ethylhexyl) phthalate, $10=$ dicyclohexyl phthalate, $11=$ dibutoxyethyl phthalate, $12=$ di- $n$-octyl phthalate, $13=$ dinonyl phthalate, $14=$ diphenyl phthalate.

rate of $5^{\circ} \mathrm{C} \min ^{-1}$ then to $215^{\circ} \mathrm{C}$ at the rate of $3^{\circ} \mathrm{C}$ $\min ^{-1}$ for $\mathrm{PC}_{11} \mathrm{CuC}_{12}$, the chromatogram for the separation of phthalates is shown in Fig. 11. Only 12 peaks were observed for these compounds. As 


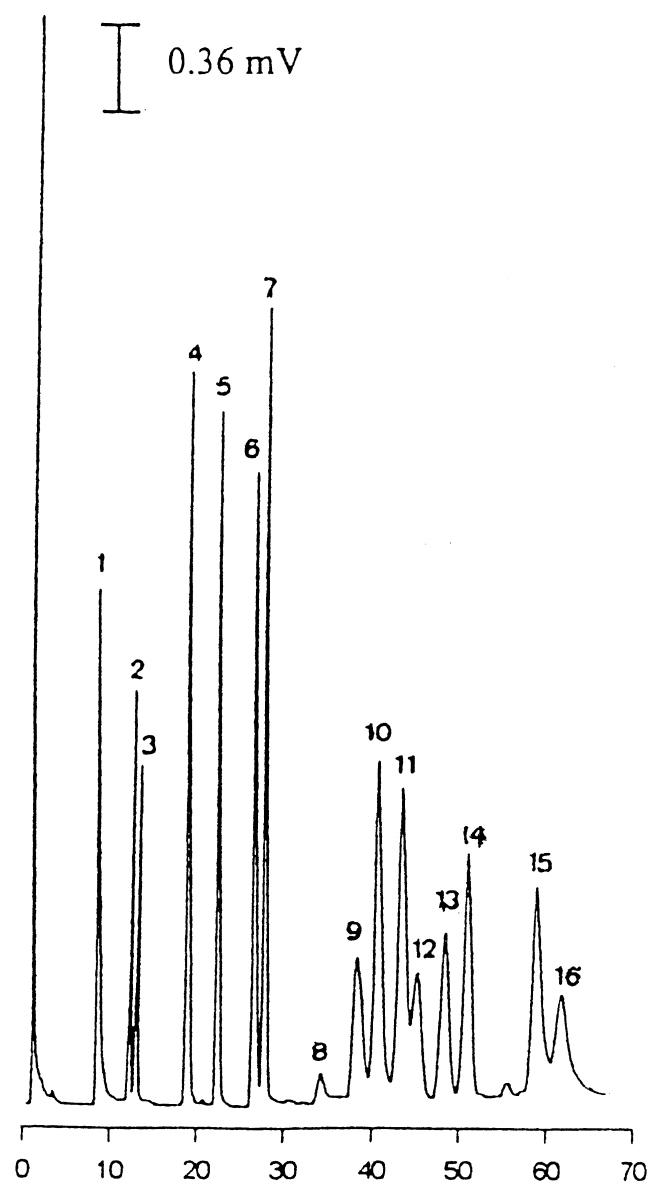

\section{Retention time (min)}

Fig. 10. Chromatogram for the separation of phthalates at temperature program condition with capillary column via dynamic coating $\mathrm{P}_{-} \mathrm{C}_{11} \mathrm{CuC}_{18}$. Stationary phase: wall coated with $\mathrm{P}$ $\mathrm{C}_{11} \mathrm{CuC}_{18}(10 \mathrm{~m} \times 250 \mu \mathrm{m}$ I.D. $)$, injection volume, $1 \mu \mathrm{l}$, injector temperature: $350^{\circ} \mathrm{C}$, inlet pressure, $15 \mathrm{kPa}$ (hold $30 \mathrm{~min}$ ) to $10 \mathrm{kPa}$ at $-3 \mathrm{kPa} \min ^{-1}$, split ratio, $1 / 40$, carrier gas: nitrogen, sample concentration: $825 \mu \mathrm{g} \mathrm{ml}^{-1}$, column temperature: $110^{\circ} \mathrm{C}$ (hold 2 min) to $195^{\circ} \mathrm{C}$ (hold $10 \mathrm{~min}$ ) then to $215^{\circ} \mathrm{C}$ at $3^{\circ} \mathrm{C} \mathrm{min}{ }^{-1}$. Peaks: $1=$ dimethyl phthalate, $2=$ diethyl phthalate, $3=$ diisopropyl phthalate, $4=$ diisobutyl phthalate, $5=\mathrm{di}-n$-butyl phthalate, $6=$ dimethoxyethyl phthalate, $7=$ di- $n$-amyl phthalate, $8=$ diisoheptyl phthalate, $9=$ diheptyl phthalate, $10=$ butylbenzyl phthalate, $11=$ di-(2-ethylhexyl) phthalate, $12=$ dicyclohexyl phthalate, $13=$ dibutoxyethyl phthalate, $14=$ di- $n$-octyl phthalate, $15=$ dinonyl phthalate, $16=$ diphenyl phthalate.

expected, a better separation was demonstrated for $\mathrm{P}-\mathrm{C}_{11} \mathrm{CuC}_{18}$ than $\mathrm{P}-\mathrm{C}_{11} \mathrm{CuC}_{12}$. Meanwhile a stronger interaction was indicated for most phthalates toward P-C ${ }_{11} \mathrm{CuC}_{18}$.

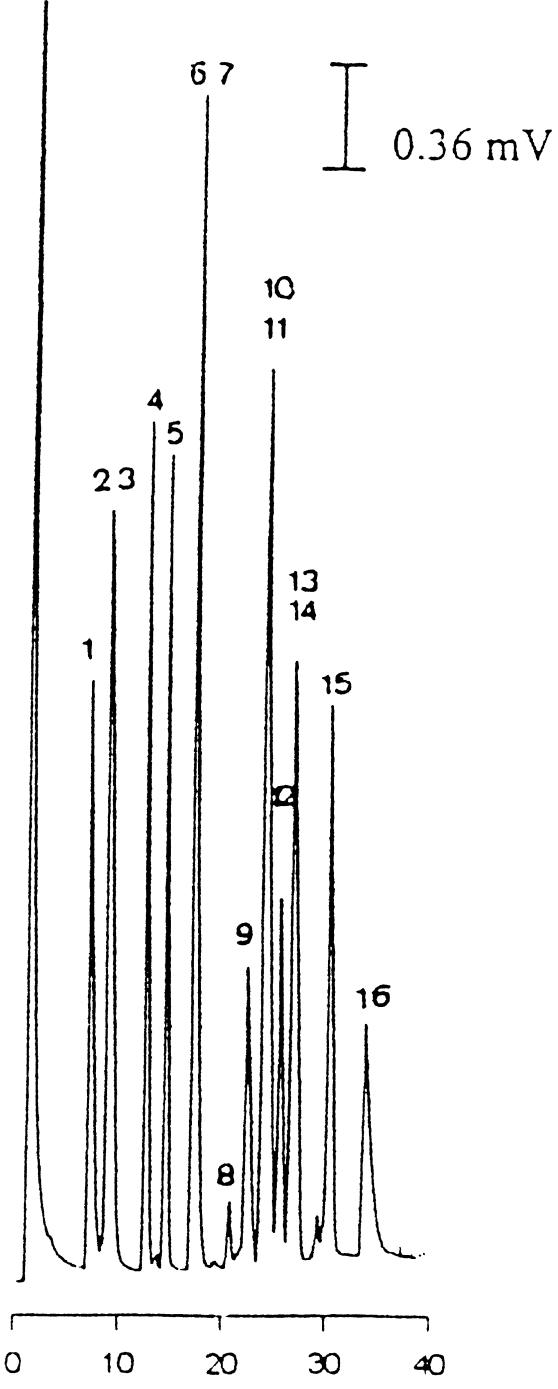

\section{Retention time (min)}

Fig. 11. Chromatogram for the separation of phthalates at temperature program condition with capillary column via dynamic coating $\mathrm{P}-\mathrm{C}_{11} \mathrm{CuC}_{12}$. Conditions as in Fig. 10, except inlet pressure, $10 \mathrm{kPa}$ (hold $30 \mathrm{~min}$ ) to $5 \mathrm{kPa}$ at $-3 \mathrm{kPa} \min ^{-1}$ and column temperature, $110^{\circ} \mathrm{C}$ (hold $2 \mathrm{~min}$ ) to $180^{\circ} \mathrm{C}$ (hold $10 \mathrm{~min}$ ) at $5^{\circ} \mathrm{C} \min ^{-1}$ then to $215^{\circ} \mathrm{C}$ at $3^{\circ} \mathrm{C} \mathrm{min}{ }^{-1}$. Peaks as in Fig. 10 .

\section{Conclusions}

In this report, the same spacer but with different ligands was introduced into the metallomesogens. The variation of the separation time between col- 
umns prepared by static and dynamic methods indicates that capillary columns with different film thickness strongly influence the retention time of the analytes. Compared with the results shown in Ref. [24] (30 $\mathrm{m} \times 0.53 \mathrm{~mm}$ I.D.), only a half length and smaller inner diameter capillary column $(15 \mathrm{~m} \times 0.25$ $\mathrm{mm}$ I. D.) was needed in this work. The results showed that the modification of siloxane polymer with metallomesogens seems more efficient than the parent one because of the new stationary phase more or less involving shape selectivity and ligand exchange separation mechanism.

$\mathrm{P}-\mathrm{C}_{11} \mathrm{CuC}_{18}$ has a ligand with a longer alkyl chain length than that of $\mathrm{P}-\mathrm{C}_{11} \mathrm{CuC}_{12}$. Therefore the stationary phase of the former would provide a greater hydrophobic force and a more unsymmetrical molecule than the latter. This results in a higher selectivity toward the phthalates with somewhat polar character. Additionally, an evident phenomenon was that only 12 peaks were observed for the 16 phthalate esters with $\mathrm{P}_{-} \mathrm{C}_{11} \mathrm{CuC}_{12}$, while 16 phthalates were nearly completely separated with the $\mathrm{P}-\mathrm{C}_{11} \mathrm{CuC}_{18}$. However, we can conclude that the more symmetrical and disk-like shape $\mathrm{P}-\mathrm{C}_{11} \mathrm{CuC}_{12}$ might be a better stationary phase for compounds with length similar to breadth.

\section{Acknowledgements}

The authors thank the National Science Council of the Republic of China, Taiwan, for financial support.

\section{References}

[1] A.M. Giroud-Godquin, J.C. Marchon, D. Guillon, A. Skoulios, J. Phys. Lett. 45 (1984) L681.
[2] H. Abied, D. Guillon, A. Skoulios, P. Weber, J.C. Marchon, A.M. Giroud-Godquin, Liq. Cryst. 2 (1987) 269.

[3] D. Demus, J. Goodby, G.W. Gray, H.W. Spiess, V. Vill, in: Handbook of Liquid Crystals, Fundamentals, Vol. 1, VCH, Weinheim, 1998, p. 857.

[4] L. Oriol, J.L. Serrano, Adv. Mater. 7 (1995) 348.

[5] A. Altomare, L. Andruzzi, F. Ciardelli, N. Tirelli, R. Solaro, Polym. Prep. 39 (1998) 272.

[6] A.A. Craig, L. Winchester, P.C. Madden, P. Larcey, L.W. Hamley, C.T. Imrie, Polymer 39 (1998) 1197.

[7] N. Carter, W.A. MacDonald, D. Pitman, T.G. Ryan, Polymer 40 (1999) 7233.

[8] P. Martinoty, L. Hilliou, M. Mauzac, L. Benguigui, D. Collin, Macromolecules 32 (1999) 1746.

[9] J.L. Serrano (Ed.), Metallomesogens - Synthesis, Properties, and Applications, VCH, Weinheim, 1996.

[10] C.C. Hu, C.Y. Liu, Anal. Chim. Acta 332 (1996) 23.

[11] C.Y. Liu, C.C. Hu, C.L. Yang, J. Chromatogr. A 773 (1997) 199.

[12] C.Y. Liu, C.C. Hu, J.L. Chen, K.T. Liu, Anal. Chim. Acta 384 (1999) 51.

[13] C.Y. Liu, J.L. Chen, C.C. Shiue, K.T. Liu, J. Chromatogr. A 862 (1999) 65.

[14] W. Wasiak, I. Rykowska, Anal. Chim. Acta 378 (1999) 101.

[15] V. Schurig, W. Buerkle, K. Hintzer, R. Weber, J. Chromatogr. 475 (1989) 23.

[16] W. Wasiak, W. Urbaniak, J. Chromatogr. A 757 (1997) 137.

[17] C.F. Yeh, S.D. Chyueh, W.S. Chen, J.D. Fan, C.Y. Liu, J. Chromatogr. 630 (1993) 275.

[18] K. Holadova, J. Hajslova, Int. J. Environ. Anal. Chem. 59 (1995) 43.

[19] M. Castillo, D. Barcelo, Trends Anal. Chem. 16 (1997) 574.

[20] M. Castillo, D. Barcelo, A.S. Pereira, F.R. Aquino Neto, Trends Anal. Chem. 18 (1999) 26.

[21] A. Penalver, E. Pocurull, F. Borrull, R.M. Marce, J. Chromatogr. A 872 (2000) 191.

[22] C.A. Staples, D.R. Peterson, T.F. Parkerton, W.J. Adams, Chemosphere 35 (1997) 667.

[23] S. Jobling, T. Reynolds, R. White, M.G. Parker, J.P. Sumper, Environ. Health Persp. 103 (1995) 582.

[24] Chromatography Product Guide, Restek International, 1999, p. 403. 